Article

\title{
The Role of NOX4 in Parkinson's Disease with Dementia
}

\author{
Dong-Hee Choi ${ }^{1,2, *}$, In-Ae Choi ${ }^{1}$, Cheol Soon Lee ${ }^{1}$, Ji Hee Yun ${ }^{1}$ and Jongmin Lee ${ }^{1,3, *(D)}$ \\ 1 Center for Neuroscience Research, Institute of Biomedical Science and Technology, Konkuk University, \\ Seoul 05029, Korea; adia86@naver.com (I.-A.C.); slaoa1428@naver.com (C.S.L.); bsea78@empas.com (J.H.Y.) \\ 2 Department of Medical Science Konkuk University School of Medicine, Konkuk University, \\ Seoul 05029, Korea \\ 3 Department of Rehabilitation Medicine, Konkuk University School of Medicine, Konkuk University, \\ Seoul 05029, Korea \\ * Correspondence: dchoi@kku.ac.kr (D.-H.C.); leej@kuh.ac.kr (J.L.); Tel.: +82-2-2049-6012 (D.-H.C.); \\ Tel: +82-2-2030-5345 (J.L.);
}

Received: 31 December 2018; Accepted: 1 February 2019; Published: 6 February 2019

\begin{abstract}
The neuropathology of Parkinson's disease with dementia (PDD) has been reported to involve heterogeneous and various disease mechanisms. Alpha-synuclein ( $\alpha$-syn) and amyloid beta $(\mathrm{A} \beta)$ pathology are associated with the cognitive status of PDD, and NADPH oxidase (NOX) is known to affect a variety of cognitive functions. We investigated the effects of NOX on cognitive impairment and on $\alpha$-syn and A $\beta$ expression and aggregation in PDD. In the 6-hydroxydopamine (6-OHDA)-injected mouse model, cognitive and motor function, and the levels of $\alpha$-syn, A $\beta$, and oligomer A11 after inhibition of NOX4 expression in the hippocampal dentate gyrus (DG) were measured by the Morris water maze, novel object recognition, rotation, and rotarod tests, as well as immunoblotting and immunohistochemistry. After 6-OHDA administration, the death of nigrostriatal dopamine neurons and the expression of $\alpha$-syn and NOX1 in the substantia nigra were increased, and phosphorylated $\alpha$-syn, A $\beta$, oligomer A11, and NOX4 were upregulated in the hippocampus. 6-OHDA dose-dependent cognitive impairment was observed, and the increased cognitive impairment, $\mathrm{A} \beta$ expression, and oligomer A11 production in 6-OHDA-treated mice were suppressed by NOX4 knockdown in the hippocampal DG. Our results suggest that increased expression of NOX4 in the hippocampal DG in the 6-OHDA-treated mouse induces A $\beta$ expression and oligomer A11 production, thereby reducing cognitive function.
\end{abstract}

Keywords: Parkinson's disease; cognitive impairment; hippocampus; alpha-synuclein; amyloid beta; A11 oligomer; NADPH oxidase

\section{Introduction}

Parkinson's disease (PD) is a common progressive neurodegenerative disease. The main neuropathological feature of PD is the loss of dopaminergic neurons [1]. Patients with PD have a high cognitive impairment and the disease has a serious negative impact on quality of life. It is now proven that $20 \%-40 \%$ of patients with PD will have a cognitive deficiency early in their illness. In addition, the risk of dementia in these patients is six times higher than it is in age-matched controls, and $80 \%$ of patients are expected to develop dementia after 20 years [2]. Parkinson's neuropathology with dementia (PDD) is heterogeneous and involves several disease mechanisms [3]. Alpha-synuclein ( $\alpha$-syn) pathology in the brainstem and cerebral cortex seems to exhibit the most potent neuropathological correlation with the dementia that occurs in PD [4]. Despite the central role of $\alpha$-syn pathology in PDD, some studies have found that $\mathrm{A} \beta$ plaques and tau neurofibrillary tangles, 
a characteristic pathological cause of Alzheimer disease (AD), are related to the cognitive status of PDD [4-9]. Neuropathological examinations using a recently developed molecular imaging approach showed that the production of amyloid plaques is common in PDD with Lewy body dementia [5,10-14]. In $50 \%$ of patients with PDD, $A \beta$ plaques and tau-containing nerve fibers are entangled, which can aggravate the prognosis of disease via synergism with $\alpha$-syn pathology [4].

Emerging data on cognitive impairment in PD support the role of the hippocampus in cognitive function $[15,16]$. The hippocampus, which is a structure that exists in the temporal lobe, is involved in learning and memory processes [17,18]. Hippocampal dysfunction may account for the high prevalence of dementia at the stage of progression of PD [1]. Neuropathological studies have shown a link between the severity of cognitive impairment in PD and the degree of deposition of Lewy bodies and Lewy neurites in the hippocampus, suggesting an important role for hippocampal structures in cognitive impairment $[1,19]$. Imaging studies that examined the association between cognitive impairment in PD and hippocampal abnormalities [20-22] have revealed that the hippocampus affects PDD induction [20-22].

Recently, we reported that cognitive dysfunction in a rat model of vascular dementia is associated with an increase in the hippocampal neuronal NADPH oxidase (NOX) 1 [23]. New evidence indicates that NOX oxidases are involved in the cognitive dysfunction observed in various diseases [24]. Several important findings show that increased NOXs are observed in postmortem brain tissues of patients with AD and mild cognitive impairment (MCI) $[25,26]$. Studies of postmortem brain tissues of AD patients demonstrated an upregulation of the p67phox, p47phox, and p40phox isoforms and an increase in NOX enzymatic activity [25]. In another study of patients with MCI, NOX activity was increased in the temporal gyrus compared with that in the control group, and gp91phox and p47phox were upregulated in microglia and neurons [26]. These studies suggest that increased NOX-related redox pathways may contribute to AD progression [24-26]. The role of NOX in the cognitive dysfunction of PDD has not been established. Therefore, we investigated the effect of NOX on neuropathies such as $\alpha$-syn and $A \beta$ formation related with cognitive impairment of PDD.

\section{Results}

2.1. Motor Deficit, Loss of TH+ Cells, Increased Expression of $\alpha$-Synuclein and NOX1 in the 6-OHDA-Lesion Side of the Striatum and Substantia Nigra

To evaluate motor function, we performed a rotation test with apomorphine (APO). APO-induced rotations toward the undamaged side were induced in 6-OHDA-treated mice (Figure 1a). Quantitative data showed a significant difference in the number of rotations between the 6-OHDA-injured mice and the control mice at 4 weeks after 6-OHDA injection. The number of rotations was increased, depending on 6-OHDA doses $(\mathrm{F}(3,44)=8.881, p<0.01 ; p<0.001$, Figure 1a). Unilateral medial forebrain bundle (MFB) lesions resulted in significant losses of tyrosine hydroxylase (TH) immunoreactive dopaminergic neurons in the striatum and substantia nigra (SN) in the 6-OHDA-lesion side (Figure 1b). We reported previously an increase in the expression of $\alpha$-synuclein ( $\alpha$-syn) and NOX1 in the SN of mice or rats treated with paraquat or 6-OHDA [27-29]. In the 6-OHDA-injected mouse model, the expression of $\alpha$-syn and NOXs was examined. We confirmed that the expression of $\alpha$-syn was increased in 6-OHDA-treated mice. Similarly, the expression of NOX1 was increased after treatment with 6-OHDA, while the expression of NOX4 was not changed (Figure 1c,d). 
(a)

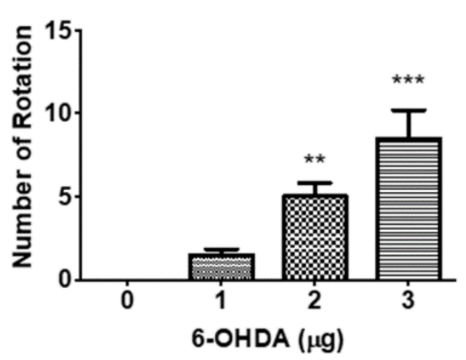

(b)

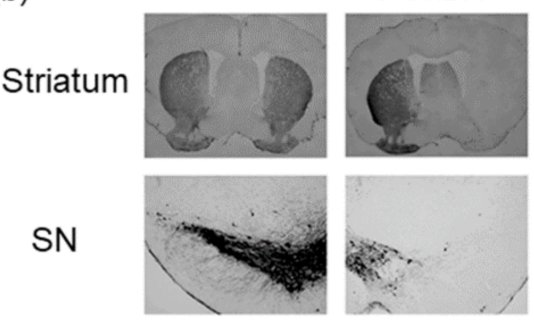

(c)

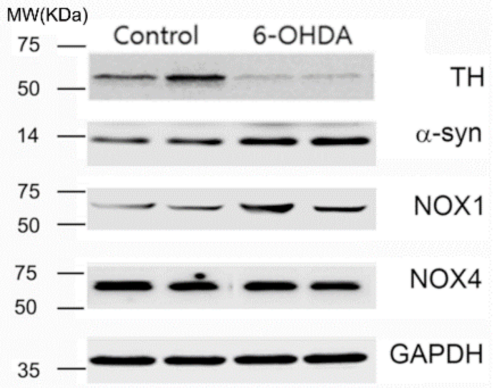

(d)

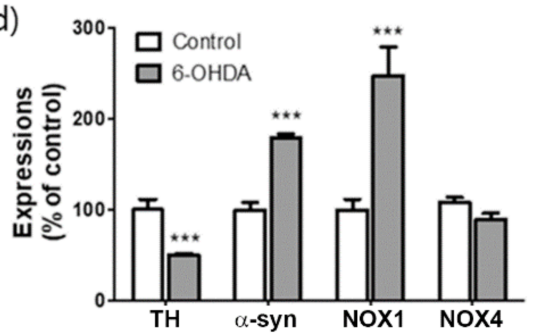

Figure 1. Evaluations of motor performance, dopaminergic neuronal death, expressions of $\alpha$-synuclein and NOX1 in the 6-OHDA-induced PD mouse. (a) Total apomorphine (APO)-induced rotation numbers were counted at 4 weeks after 6-OHDA injection. (b) Representative photomicrographs of tyrosine hydroxylase $(\mathrm{TH})$ staining in the mouse striatum and substantia nigra (SN) sections. (c) Results are presented as the mean $\pm \mathrm{SEM}, n=6$. (c) Representative photomicrographs of western blots for $\alpha$-synuclein ( $\alpha$-syn), NOX1, NOX4, and GAPDH in total lysates of the SN tissue at $4 \mathrm{w}$ after 6-OHDA injection. MW, molecular weight; KDa, KiloDalton. (d) Signal intensities were measured using Quantity One software and are shown as a percentage of control. GAPDH was considered as an internal control. Results are presented as the mean $\pm \operatorname{SEM}, n=6{ }^{* * *} p<0.001$ vs. control.

\subsection{Cognitive Deficit Induced by MFB Injury Caused by 6-OHDA Injection}

The cognitive deficit of mice with unilateral MFB lesions was detected using the Morris water maze task. The latency of locating the platform and search errors were significantly increased in the spatial learning trials in a 6-OHDA dose-dependent manner (two-way repeated-measures analysis of variance (ANOVA), $\mathrm{F}(3,44)=12.46, p<0.05 ; \mathrm{F}(3,44)=17.53, p<0.01$, Figure 2a,b). There was no significant difference in the swimming speed $(\mathrm{F}(3.44)=1.860, p=0.1689$, Figure $2 \mathrm{c})$. There was a difference between the groups regarding the percentage of time spent in the target quadrant and in platform crossing number in the probe trials of $30 \mathrm{~s}(\mathrm{~F}(3,44)=5.683, p<0.01$, Figure 2d,e). The percentage of time spent in the target quadrant and the number of target site crossovers were notably decreased in the probe trials in rats injected with $3 \mu \mathrm{g} / \mathrm{kg}$ of $6-\operatorname{OHDA}(\mathrm{F}(3,44)=6.303, p<0.05$, Figure $2 d, a, e)$ compared with those in control mice. 
(a)

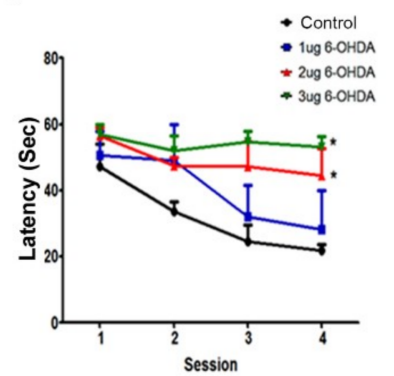

(d)

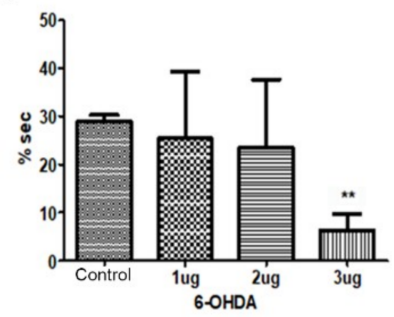

(b)

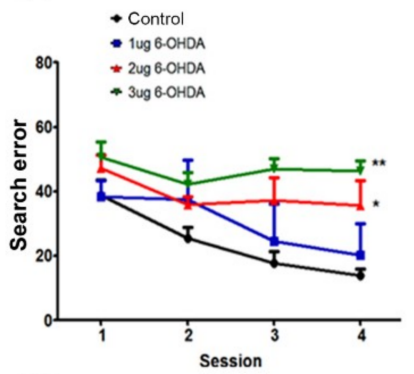

(e)

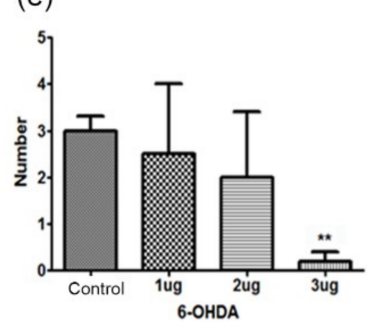

(c)

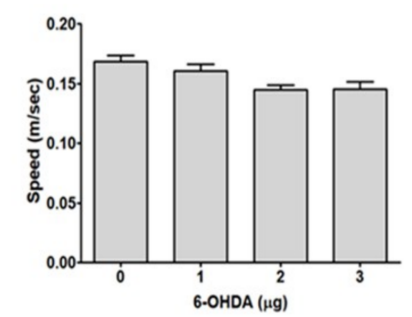

Figure 2. Cognitive impairment in the 6-OHDA-induced PD mouse. Spatial memory evaluation using the time latency (a), search error (b), swimming speed (c), percentage of time in target quadrant (d), and time latency in visible platform test (e). $n=12$ per group, ${ }^{*} p<0.05,{ }^{* *} p<0.01$ vs. control.

\subsection{Levels of Alpha-Synuclein and Amyloid Beta Pathology in Animals with MFB Injury Caused by} 6-OHDA Injection

Previous studies have shown that PDD has an increased $\alpha$-syn pathology in the cerebral cortex, limbic area, parahippocampal gyrus, or anterior cingulate gyrus compared with PD [4,7,30,31]. Moreover, amyloid beta $(\mathrm{A} \beta)$ pathology in PDD is correlated with cognitive impairment [4].

Therefore, the expression of $\alpha$-syn, phosphorylated $\alpha$-syn (p- $\alpha$-syn), A $\beta$, and A11 oligomers was confirmed in the cortex, striatum, $\mathrm{SN}$, and hippocampus of 6-OHDA-treated mice by dot blot analysis. $\alpha$-Syn expression was increased in the striatum and SN $(p<0.01, n=6$, Figure 3a,f), and p- $\alpha$-syn was significantly upregulated in the SN and hippocampus $(p<0.05 ; p<0.01, n=6$, Figure 3b,f). Specifically, the expression of $\mathrm{A} \beta$ was markedly increased in the hippocampus $(p<0.01, n=6$, Figure 3c,h), and the A11 oligomer was significantly increased in SN and hippocampus $(p<0.05 ; p<0.01, n=6$, Figure $3 d, g)$. Therefore, new evidence suggests that $p$ - $\alpha$-syn, $A \beta$, and A11 oligomers are upregulated in the hippocampus of the PDD animal model (Figure 3). 
(a)

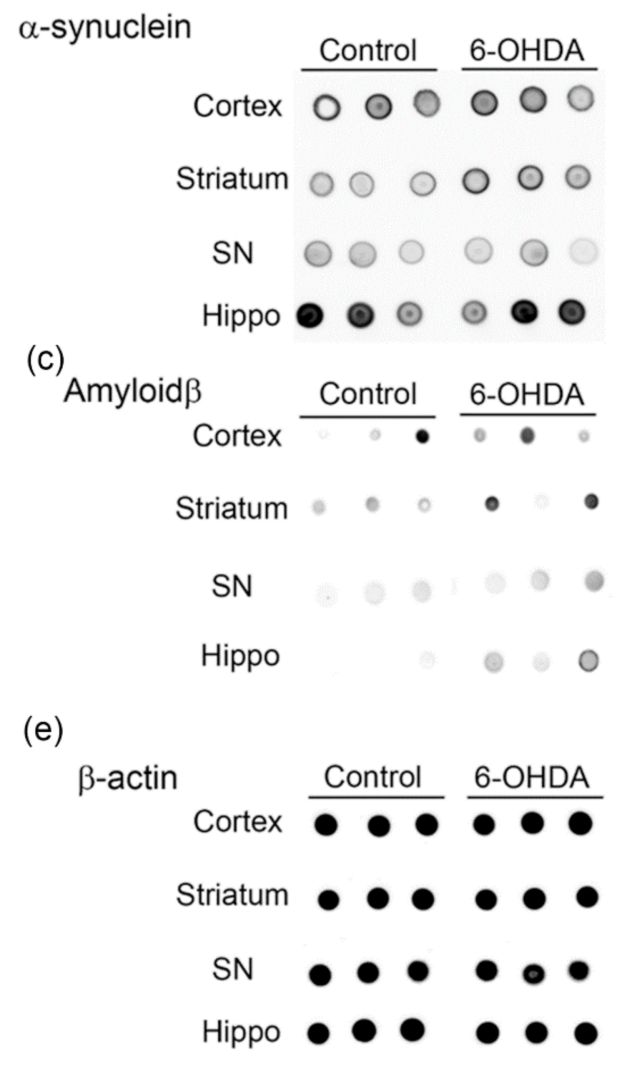

(b)

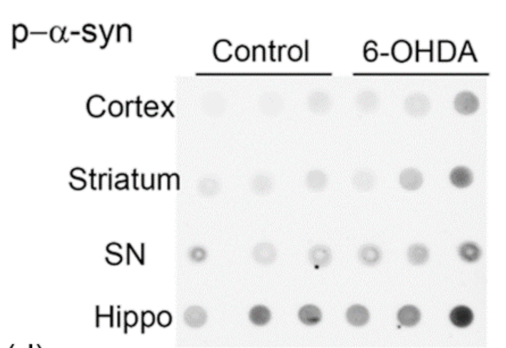

(d)
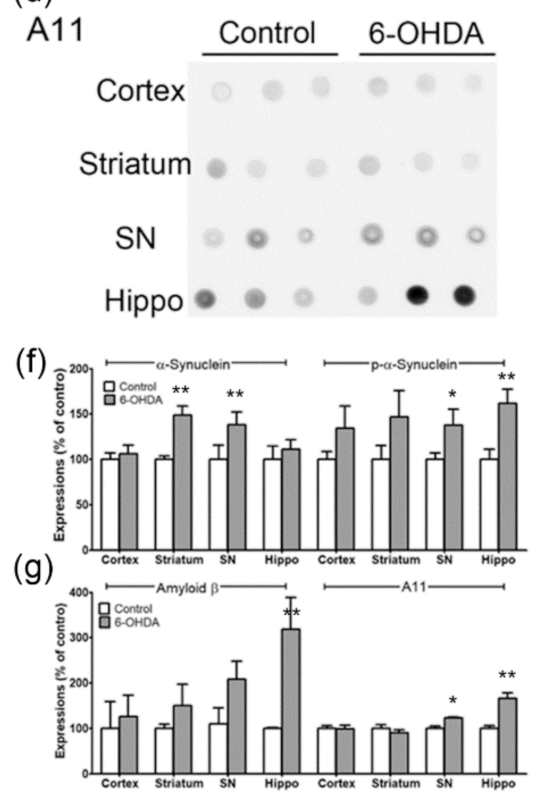

Figure 3. Expressions of $\alpha$-synuclein, $\mathrm{p}-\alpha$-syn, amyloid $\beta$, A11 oligomers in the cortex, striatum, $\mathrm{SN}$, and hippocampus of 6-OHDA-injectecd PD mice. Representative immunoblot analysis of (a) $\alpha$ synuclein, (b) p- $\alpha$-syn, (c) amyloid $\beta$ (d) A11 oligomers, and (e) $\beta$-actin in cortex, striatum, $\mathrm{SN}$, and hippocampus of 6-OHDA-injectecd PD mice. ( $f$ and $\mathbf{g}$ ) All expression levels were quantified using Quantity One software and normalized against $\beta$-actin. The results are expressed as a percentage of control. Data are shown as the mean \pm SEM. $n=6 /$ group, ${ }^{*} p<0.05,{ }^{* *} p<0.01$, vs. control. $p-\alpha$-syn, phosphorylated $\alpha$-synuclein; SN, substantia nigra; Hipp, hippocampus.

2.4. Increased Levels of Phosphorylated Alpha-Synuclein, Aggregated Amyloid Beta, and NADPH Oxidase-4 in the Hippocampus

Hippocampal atrophy is associated with MCI in PD [15]. The hippocampus is an important brain structure that is related to learning and memory [32,33]. We attempted to identify molecular changes in the hippocampal region that occur during cognitive impairment in the model of PD. The expression of $\alpha$-syn and NOXs (Nox1, Nox2, and Nox4) in the hippocampus was detected by western blot analysis (Figure 4a,b). P- $\alpha$-syn and NOX4 were increased in total lysates of the hippocampal tissues of mice injected with 6-OHDA (Figure 4a,b). The immunohistochemical analysis revealed that $\alpha$-syn was expressed in the hilar (CA4) mossy fiber terminal fields originating from the dentate gyrus (DG) of the hippocampus (Figure 4c). In addition, $\alpha$-syn immunostaining (red) was mostly colocalized with neuron-specific class III beta-tubulin (Tuj-1)-positive neurons, which were immunostained in green in the hilar (CA4) mossy fiber terminal fields (as identified by the yellow staining observed after merging the two images). P- $\alpha$-syn expression was greatly increased in the DG granule cell layer of the hippocampus at 4 weeks after 6-OHDA operation compared with that observed in sham-operated animals ( $p<0.01, n=6$, Figure $4 \mathrm{~d}$,e). Interestingly, $A \beta$ expression was also greatly increased in the hilar (CA4) mossy fiber terminal fields, supragranular layer (SG), and outer and middle molecular layers of 
the fascia dentata $(p<0.001, n=6$, Figure $4 \mathrm{f}, \mathrm{h})$. A $\beta$ immunostaining (red) was mostly colocalized with Tuj-1-positive neurons, which were immunostained in green in the hilar (CA4) mossy fiber terminal fields (as identified by the yellow staining observed after merging the two images). NOX4 (green) and oligomer A11 (red) levels were increased in the hilar (CA4) mossy fiber terminal fields and granule cell layer of the DG. These two proteins were mostly colocalized, as identified by the yellow staining observed after merging the two images ( $p<0.01, n=6$, Figure $4 \mathrm{~g}$, h).
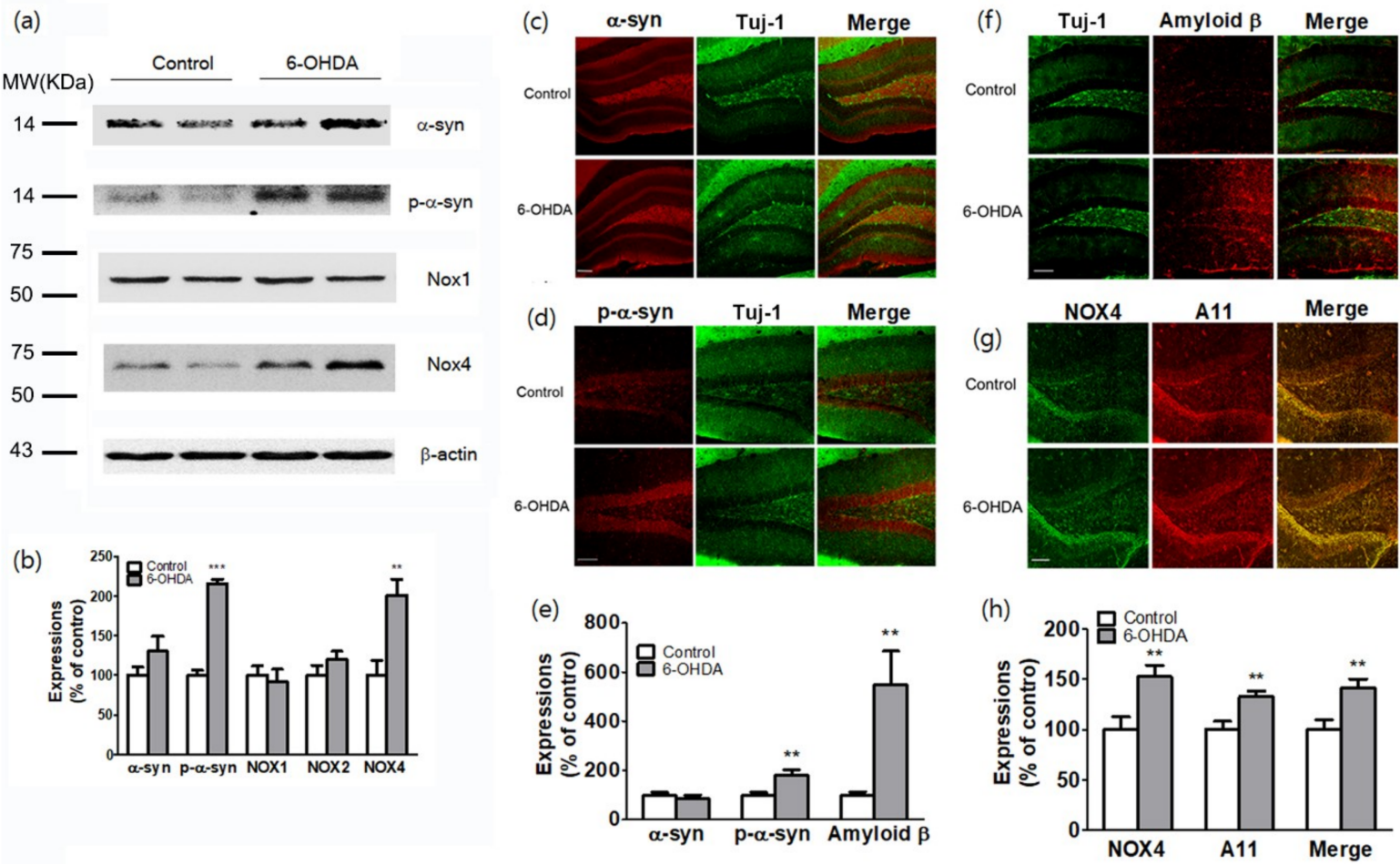

Figure 4. Expressions of p- $\alpha$-syn, amyloid $\beta$, A11 oligomers, and NOX4 in the hippocampus of 6-OHDA-injectecd PD mice. (a) Representative western blot analysis of $\alpha$-syn, p- $\alpha$-syn, NOX1, NOX2, and NOX4 in the hippocampus of 6-OHDA-injectecd PD mice. MW, molecular weight; KDa, KiloDalton. (b) Expression levels were quantified using Quantity One software and normalized against $\beta$-actin. The results are expressed as a percentage of control. Data are shown as the mean \pm SEM. $n=6$ per group, ${ }^{* *} p<0.01$; ${ }^{* * *} p<0.001$, vs. control. Representative photomicrographs of $\alpha$-syn (c) and p- $\alpha$-syn (d) staining in the mouse hippocampal sections. (e) Expression levels were quantified using Quantity One software. The results are expressed as a percentage of control. Data are shown as the mean \pm SEM. $n=6$. ${ }^{* *} p<0.01$ vs. control. Representative photomicrographs of amyloid $\beta$ (f), NOX4, A11, and NOX4 and A11 co-stating (g) in the mouse hippocampal sections. (h) Expression levels were quantified using Quantity One software. The results are expressed as a percentage of control. Data are shown as the mean \pm SEM. $n=6$. ${ }^{* *} p<0.01$ vs. control. $\alpha$-syn, $\alpha$-synuclein; $\mathrm{p}$ - $\alpha$-syn, phosphorylated $\alpha$-synuclein; Tuj-1, neuron-specific class III beta-tubulin; scale bars: $50 \mu \mathrm{m}$.

To investigate the effects of these molecules on cognitive deficits in PDD model with 6-OHDA, changes in NOX4, NOX1, A $\beta$ expression and A11 oligomer production in hippocampus and behavioral changes of 6-OHDA injected mice were analyzed by Pearson correlation coefficient. There was a high correlation between cognitive impairment and A11 oligomer production, NOX4, and A $\beta$ expression, except for NOX1 expression (Figure 5). 

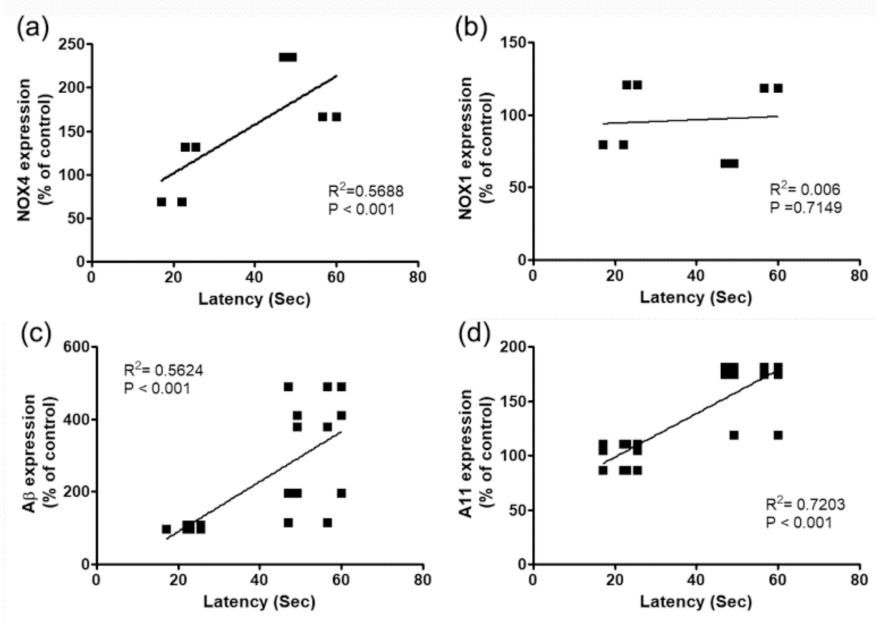

Figure 5. Relationship between the cognitive impairment and percentage of changes (\%) of NOX4 (a), NOX1 (b), and A $\beta$ expressions (c), and A11 oligomer production (d) in the hippocampus of 6-OHDA-injectecd PD mice.

2.5. Inhibition of NADPH Oxidase-4 in Hippocampal Neurons Reduced Cognitive Impairment in a PD Animal Model

To verify the role of the expression of NOX4 in the DG in the cognitive impairment observed in the PD animal model, selective inhibition of NOX4 was achieved via the stereotaxic delivery of an adeno-associated virus 2 (AAV2) containing an shRNA targeting NOX4 to the hippocampal DG (Figure $6 \mathrm{a}, \mathrm{b}, \mathrm{c}$ ). These vectors expressed the enhanced green fluorescent protein (EGFP) separately, as an index of transduction efficiency (Figure 6a). EGFP-expressing cells were detected in the DG of mice injected with scrambled shRNA/AAV2 (Scb shRNA) or Nox4 shRNA/AAV2 (Nox4 shRNA) viral particles (Figure $6 \mathrm{~b}, \mathrm{c}$ ). NOX4 expression was mostly suppressed after Nox4 shRNA viral particle injection, which implies the efficient knockdown of NOX4 expression $(p<0.001, n=6$, Figure $6 \mathrm{~b}, \mathrm{c})$. The RT-PCR and western blot analyses performed after AAV2 injection demonstrated NOX4 knockdown efficiency in hippocampal DG ( $p<0.001, n=6$, Figure $6 \mathrm{~d}$,e). NOX activities were also determined from 4 weeks post-6-OHDA administration using Scb shRNA or Nox4 shRNA viral particles. We observed that NOX activation was significantly decreased by Nox4 shRNA/AAV2 treatment at 4 weeks post-6-OHDA administration $(\mathrm{F}(3,20)=3.405, p<0.05$, Figure $6 \mathrm{f})$. 
(a)

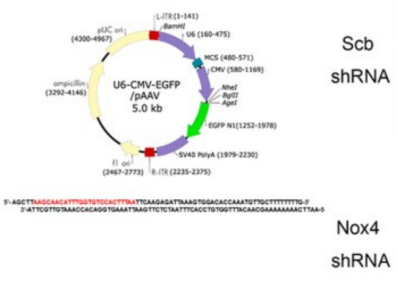

(b)

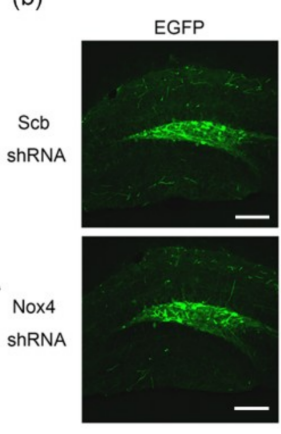

(c)

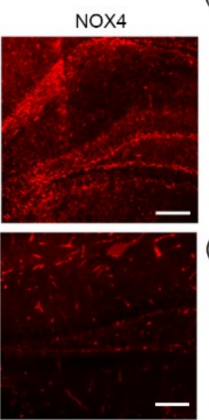

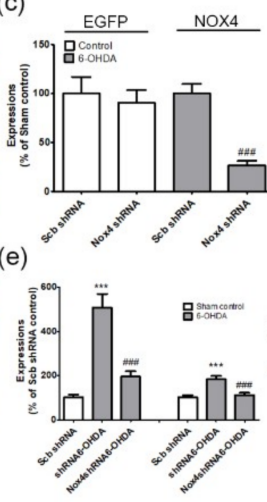

(d)

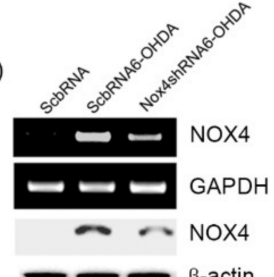

(f)

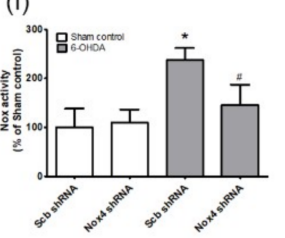

Figure 6. The transduction efficiency of scramble shRNA or NOX4 shRNA expression in hippocampus and reduced NOX4 expressions by NOX4 knockdown in 6-OHDA injected mice. (a) Establishment of U6 promoter-based NOX4 shRNA/AAV vector. The U6 promoter-driven shRNA expression system was established in the AAV vector. EGFP expression is separately controlled by a CMV promoter as a marker for the transduction efficiency. The NOX4 shRNA sequence was designed based on the siRNA sequence (boxed red nucleotides). (b) Representative photographs of tissue sections expressed EGFP (green) from mice hippocampal DG taken from mice injected with Scb shRNA/AAV2 or NOX4 shRNA/AAV2 and PBS (sham control) or 6-OHDA injection. To confirm NOX4 knockdown efficiency, NOX4 (red) expression was determined by NOX4 immunostaining in the hippocampal DG of 6-OHDA injected mice with shRNA/AAV2 or NOX4 shRNA/AAV2. (c) EGFP and NOX4 expression levels were quantified using Quantity One software. The results are expressed as a percentage of control. Data are shown as the mean \pm SEM. $n=6$. \#\#\# $p<0.001$ vs. Scb shRNA 6-OHDA. (d and e) NOX4 knockdown efficiency in the hippocampal DG was also verified by both western blot analysis and RT-PCR performed after Scb shRNA or NOX4 shRNA injection. $n=6$ per group. Expression levels were quantified using Quantity One software. The results are expressed as a percentage of control. Data are shown as the mean \pm SEM. ${ }^{* * *} p<0.001 \mathrm{vs.} \mathrm{Scb} \mathrm{shRNA} \mathrm{control;} \mathrm{\# \# \#} p<0.001$ vs. Scb shRNA 6-OHDA. (f) NOX enzyme activity was measured in lysates of hippocampal tissue at 4 weeks after 6-OHDA treatment in Scb shRNA/AAV2 or NOX4 shRNA/AAV2-injected mice. $n=6$ per group. ${ }^{*} p<$ 0.01 vs. Scb shRNA control; \# $p<0.05$ vs. Scb shRNA 6-OHDA. Scb shRNA, scrambled shRNA; scale bars $=100 \mu \mathrm{m}$.

The role of NOX4 in motor performance after 4 weeks of 6-OHDA administration was evaluated by the APO-induced rotation $(\mathrm{F}(3,44)=11.54, p<0.01)$ and the rotarod tests $(\mathrm{F}(3,44)=4.654, p<0.05)$. There was no difference between Scb shRNA and Nox4 shRNA treatment in 6-OHDA-injected mice (Figure $7 \mathrm{a}, \mathrm{b})$.

Next, we used Morris water maze (MWM) tests to assess the effects of NOX4 on cognitive function recovery in the PD model, by assessing learning and memory retention and spatial memory. Sham-operated control mice that received injection of Scb shRNAs were able to quickly find the diving platform during training, whereas mice that received Scb shRNA injections and were treated with 6-OHDA showed poor improvement during training compared with control mice (Figure 7c). The reduction in spatial memory observed in Scb shRNA-injected 6-OHDA-treated mice was significantly restored by inhibition of NOX4 using Nox4 shRNA particles (two-way repeated-measures ANOVA, $\mathrm{F}(3,44)=15.53, p<0.05$, Figure $7 \mathrm{c})$. No differences in the swimming speed were observed between the four groups $(\mathrm{F}(3,44)=1.245, p=0.3051$, Figure $7 \mathrm{~d})$. The time spent in the target quadrant and the number of platform crossings were not different between the groups in the first probe test, but the time spent in the target quadrant and the platform crossings in the second probe test differed significantly in the 6-OHDA group with inhibition of NOX4 (percentage of time spent in the target quadrant, $\mathrm{F}(3,44)$ $=25.04, p<0.001$; number of platform crossings, $\mathrm{F}(3,44)=16.45, p<0.001$, Figure 7e,f). In addition, in the novel object recognition (NOR) test, the reduction in the NOR discrimination ratio observed in 
6-OHDA-treated mice that received Scb shRNAs was reversed by the delivery of the NOX4 shRNA $(\mathrm{F}(3,44)=5.806, p<0.01$, Figure $7 \mathrm{~g})$.

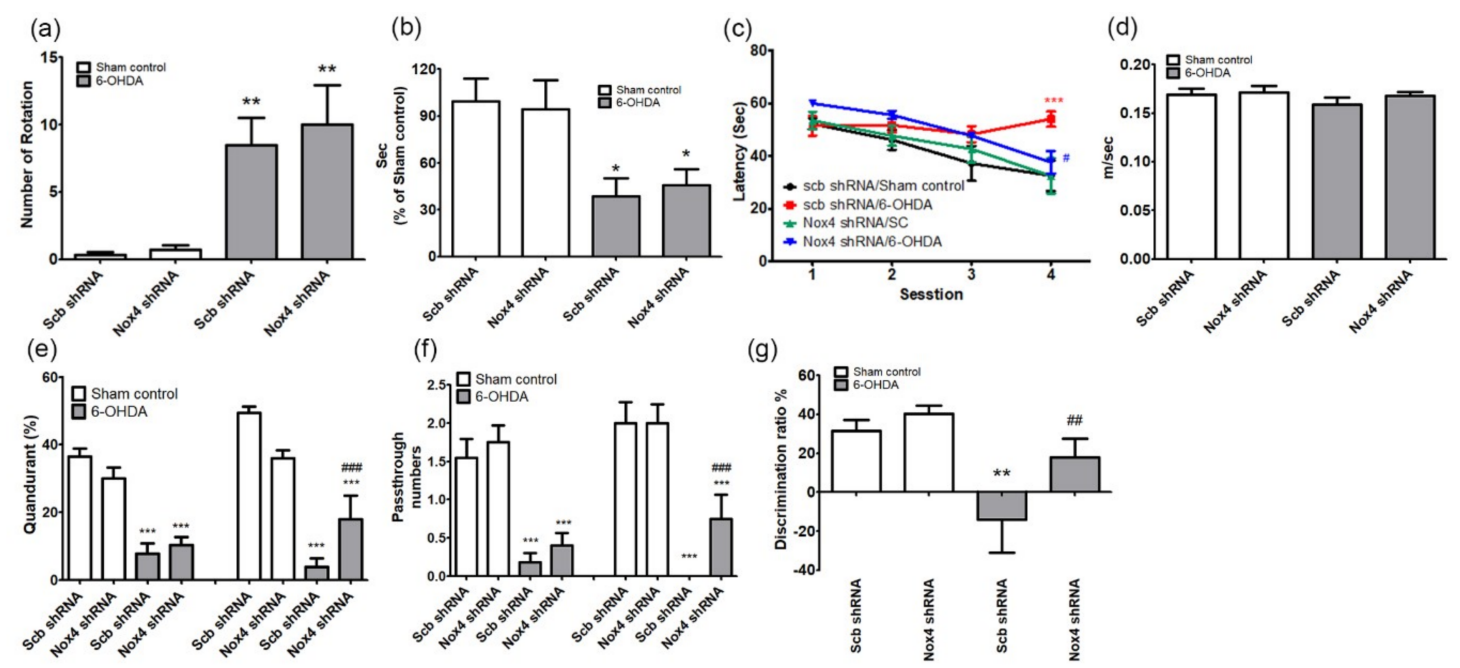

Figure 7. Inhibition of NOX4 reduces the memory impairment in the 6-OHDA-induced PD mouse. (a) Total apomorphine (APO)-induced rotation numbers; (b) retention times in rotarod tests were measured at 4 weeks after 6-OHDA injection in Scb shRNA/AAV2 or NOX4 shRNA/AAV2-injected mice. $n=12 .{ }^{*} p<0.05,{ }^{* *} p<0.01$ vs. sham control. (c-f) Spatial memory evaluation using the time latency (c), swimming speed (d), percentage of time in target quadrant (e), and (f) number of passes through the platform. (g) The novel object recognition test was performed, exploratory time spent for novel objects was recorded, and the discrimination ratio was calculated. $n=12$ per group, ${ }^{*} p<$ $0.05,{ }^{* *} p<0.01,{ }^{* * *} p<0.001$ vs. Scb shRNA sham control; $\# p<005, \# \# p<0.01, \# \# \# p<0.001$ vs. Scb shRNA 6-OHDA.

\subsection{NOX4 Knockdown Reduces 6-OHDA-Mediated Amyloid Beta and A11 Oligomer Upregulation in the Hippocampus}

To investigate the mechanism of inhibition of cognitive impairment caused by NOX4 knockdown, we examined the effects of NOX4 upregulation in the hippocampal DG of MFB-injured mice on the expression of $\alpha$-syn and $A \beta$ on protein aggregation in hippocampal tissues. The levels of $\alpha$-syn, $A \beta$, and protein aggregation were investigated in the hippocampus of each group of animals by dot blot and immunohistochemical analyses.

We found that $\alpha$-syn expression did not differ between groups and that the increase in the levels of $\mathrm{p}-\alpha$-syn observed in the 6-OHDA group was not present in the group with NOX4 inhibition (Figure 8a,b). A $\beta$ expression and A11 oligomer production were significantly increased in the Scb shRNA plus 6-OHDA groups, and these increases were reversed by NOX4 inhibition (amyloid $\beta$, $\mathrm{F}(3,20)=34.28, p<0.001 ; \mathrm{A} 11, \mathrm{~F}(3,20)=19.42, p<0.001 ;$ Figure 8a,b). Immunohistochemical evaluations revealed a significant increase in the immunoreactivity of $A \beta$ in the hippocampus of mice that received injection of 6-OHDA in the MFB; this increase was reversed in the group exposed to 6-OHDA in which NOX4 was knocked down $(p<0.001, n=6$, Figure $8 c, d)$. The involvement of NOX4 on production of the A11 oligomers in the hippocampus of 6-OHDA treated mice was also evaluated; the significant increase in A11 immunoreactivity observed in the hippocampus of mice exposed to Scb shRNA plus 6-OHDA was reversed by NOX4 knockdown (Nox4 shRNA plus 6-OHDA) $(p<0.001$, Figure 8e,f). Taken together, our results are highly suggestive of an active role for NOX4 in hippocampal A $\beta$ pathology induced by 6-OHDA injection into the MFB, both at the transcriptional level and via a posttranslational aggregation mechanism. 
(a)

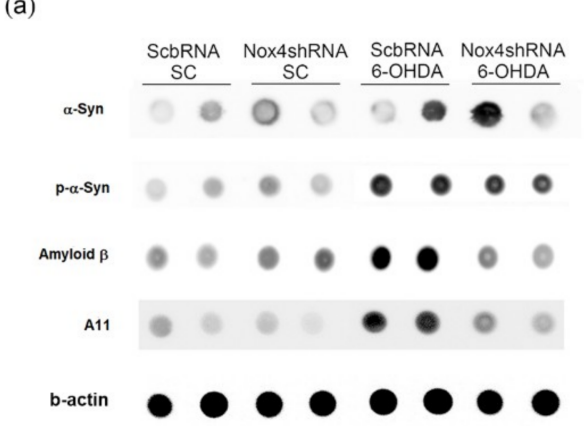

(b)

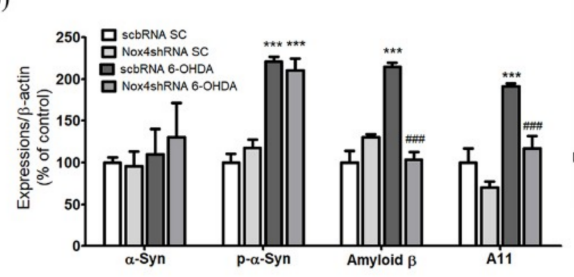

(c)

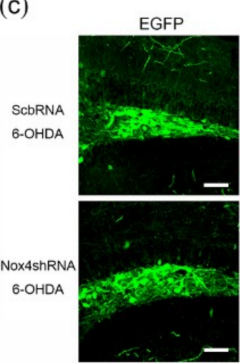

(e)

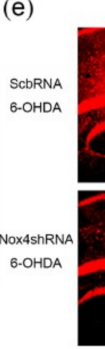

A11

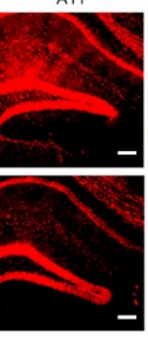

Amyloid

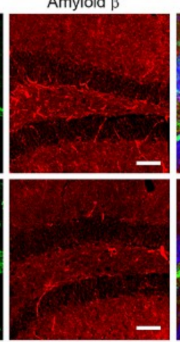

Topro3

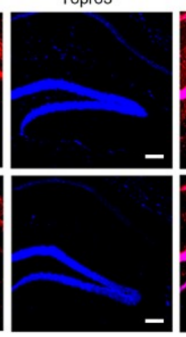

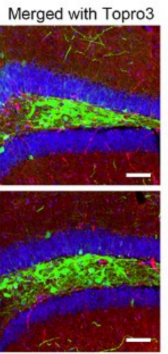

Merge

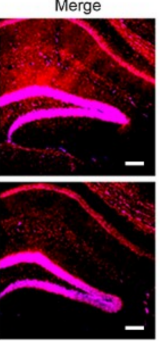

(d)

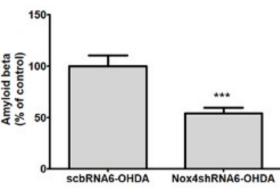

(f)

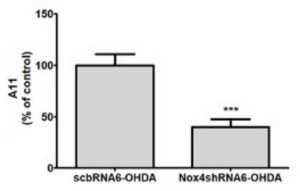

Figure 8. Inhibition of NOX4 reduced expressions of amyloid $\beta$ and A11 oligomers in the hippocampus of 6-OHDA-injectecd PD mice. Representative immunoblot analyses of (a) $\alpha$-syn, p- $\alpha$-syn, amyloid $\beta$, A11 oligomers, and $\beta$-actin in the hippocampus of 6-OHDA-injectecd PD mice. (b) All expression levels were quantified using Quantity One software and normalized against $\beta$-actin. The results are expressed as a percentage of control. Data are shown as the mean \pm SEM. $n=6$ per group, ${ }^{* * *} p<0.001$, vs. Scb shRNA SC; \#\#\# $p<0.001$ vs. Scb shRNA 6-OHDA. (c) Representative photomicrographs of cells expressing EGFP (green) represent AAV-transduced cells. Scb shRNA or NOX4 shRNA with amyloid $\beta$-positive cells is demonstrated by yellow staining after merging green (EGFP) and red (amyloid $\beta)$ images. Blue colors show the Topro3 nuclear marker. (d) Yellow stained cells were counted and quantified using Quantity One software. The results are expressed as a percentage of control. Data are shown as the mean \pm SEM. $n=6$. (e) Representative photomicrographs A11 oligomers (red) staining in the hippocampal sections of Scb shRNA 6-OHDA and NOX4 shRNA 6-OHDA mice. Blue colors show the Topro3 nuclear marker. (f) The expression level was quantified using Quantity One software. The results are expressed as a percentage of control. Data are shown as the mean \pm SEM. $n=6{ }^{* * *} p<$ 0.001 vs. Scb shRNA 6-OHDA. SC, sham control; Scb RNA, scrambled shRNA; scale bars $=50 \mu \mathrm{m}$.

\section{Discussion}

In this study, we observed cognitive impairment in a PD model in which 6-OHDA was administered to the MFB. We also demonstrated, for the first time, that this cognitive impairment was mediated by the expression and aggregation of $A \beta$ in the hippocampus and was associated with an increase in NOX4 expression in the hippocampal DG.

Accumulation of $\mathrm{p}-\alpha$-syn, $A \beta$, and NOX4 was detected in the hippocampus after MFB injury via 6-OHDA injection. In addition, hippocampal A $\beta$ expression, A11 oligomer formation, and cognitive impairment were attenuated by genetic interventions targeting NOX4 in the hippocampal DG. These results strongly indicate that NOX4-mediated hippocampal changes may serve as critical upstream processes in $\mathrm{A} \beta$ expression, A11 formation, and cognitive impairment in PDD.

We also found that dopaminergic neuronal death, a typical phenomenon in the $\mathrm{SN}$ and striatum of this PD model, and upregulation of NOX1 and $\alpha$-syn were similar to the results reported in previous studies [27-29].

Cognitive impairment without functional deficits (as a diagnosis of dementia) is a common feature of PD and is predominant in the late stage of the disease $[4,34,35]$. The prevalence of cognitive impairment in PD is $\sim 30 \%$, and $\sim 80 \%$ of patients with PD develop dementia during disease progression $[4,34,36,37]$. The incidence of progression to dementia in patients with PD is estimated to be more than four times that of the general population $[4,36,38-40]$, which has a major impact on the quality of life of patients $[4,36,38-40]$. Therefore, it is important to understand the pathophysiology 
that causes cognitive dysfunction in PD, because cognitive impairment in this disease and the onset and progression of dementia are important for patient management and prognosis [4].

The MFB lesion model [41] used in this study was suitable for mimicking PDD because it showed cognitive impairment in the Morris water maze test depending on the concentration of the 6-OHDA that was injected into the MFB (Figure 2). In this PD model, the typical nigrostriatal dopaminergic degeneration [27-29] was observed (Figure 1). Lewy bodies and neuritic pathologies in the cerebral cortex are predominant in the neuropathology of PDD compared with PD, as confirmed by $\alpha$-synuclein immunohistochemistry [3-5,30,31]. In many studies, PDD is distinguished from PD based on the global cortical and limbic $\alpha$-syn expression [4,30,42,43]. Moreover, several studies have shown that the severity of $\alpha$-syn accumulation differs in areas such as the parahippocampal gyrus or anterior cingulate gyrus $[4,7,30]$. However, even in patients with PD $[4,30,31]$ or Lewy body dementia (LBD) $[4,44,45]$, the cortical and limbic $\alpha$-syn pathology is highly dependent on the individual, and $\alpha$-syn pathology is inconsistent in patients with PDD [3,4,46]; therefore, other factors need to be studied for diagnostic accuracy. In this study, $\alpha$-syn expression was confirmed in the cortex, striatum, $\mathrm{SN}$, and hippocampus, thus confirming the $\alpha$-syn pathology reported by existing studies. Increased $\alpha$-syn expression was observed in the striatum and $\mathrm{SN}$, and $\mathrm{p}-\alpha$-syn, which has a dominant $\alpha$-syn activity, was significantly upregulated in the $\mathrm{SN}$ and hippocampus (Figure 3). In particular, the increase in the levels of p- $\alpha$-syn in the hippocampus may pinpoint a new role for the hippocampus in the cognitive impairment observed in PDD.

Although $\alpha$-syn pathology plays a key role in PDD, studies have shown that $\mathrm{A} \beta$ plaques and tau nerve fiber entanglement, which are characteristic pathological causes of $A D$, are associated with cognitive status in patients with PDD [4-9]. In the striatum of these patients, $\alpha$-syn pathological lesions $[4,43,47]$ and diffuse $\mathrm{A} \beta$ plaques (characteristic of $\mathrm{AD}$ ) were found more frequently than they were in patients with PD without dementia [4,13]; this striatal pathology has been regarded as a factor that can cause cognitive impairment. Therefore, $A \beta$ pathology, which is one of the neuropathologies of AD, may play an important role in the pathogenesis of PDD [4]. Based on this, we found that the expression of $A \beta$ in the animal model used in the present study was slightly increased in the striatum and SN and dramatically increased in the hippocampus. The level of oligomer A11 also showed a significant increase in the $\mathrm{SN}$ and hippocampus. These results suggest that $\alpha$-syn and $\mathrm{A} \beta$ pathology in the hippocampus affect the pathogenesis of PDD (Figure 3).

Studies have shown that oxidative damage caused by excessive reactive oxygen species (ROS) production affects the cognitive impairment associated with age, $\mathrm{AD}$, vascular dementia (VaD), and mild cognitive impairment $[23-26,48,49]$. Nicotinamide adenosine dinucleotide phosphate oxidase (NOX) is one of the most important factors in the formation of ROS in the brain. Recently, we demonstrated that NOX1-mediated oxidative stress plays an important role in hippocampal neuronal degeneration and cognitive dysfunction in a vascular dementia animal model [23,24]. Several studies have shown that cognitive impairment in age- or AD-related transgenic mice occurs through an increase in NOX activity and an increase in the expression of NOX2 and NOX4, which lead to oxidative stress and amyloid deposition [24,48,50-52]. In addition, an increase in the NOX-related redox mechanism was observed in postmortem brain tissues of patients with $\mathrm{AD}$, and it was suggested that these changes could lead to the progression of $\mathrm{AD}[25,26]$.

To investigate the role of NOX in the hippocampal $\alpha$-syn and A $\beta$ pathology involved in PDD, the expression of NOX in the hippocampus of 6-OHDA-treated mice was examined. We found that NOX4 was significantly upregulated in this brain structure, whereas NOX1 and NOX2 remained unchanged (Figure 4). Specifically, the expression of NOX4 dominated the DG region of the hippocampus and was colocalized with the expression of oligomer A11 (Figure 4). Changes in NOX4 expression were highly correlated with cognitive impairment (Figure 5). In mice carrying NOX 4 suppression through genetic manipulation (Figure 6), the cognitive decline that was detected after 6-OHDA administration was reduced (Figure 7) and the upregulation of $A \beta$ and increased generation of A11 oligomer were attenuated (Figure 8). These results suggest that the cognitive impairment observed in PDD is related 
to the expression of $\mathrm{A} \beta$ and the production of $\mathrm{A} 11$ oligomer, which are induced by the increased activity of NOX4 in the hippocampus.

In the present study, we used a mouse model in which 6-OHDA was administered to the MFB to investigate the cause of cognitive impairment and progression to PDD in patients with PD. We showed that the upregulation of NOX4 in the DG of the hippocampus was accompanied by cognitive impairment and led to increases in $A \beta$ expression and oligomer A11 production. In addition, it is necessary to overcome the limitations of the model by conducting studies using PDD models other than the 6-OHDA administration model, but our study may be useful for preclinical studies of new diagnostic and therapeutic technologies for PDD. In the future, it will be necessary to identify the mechanism underlying the involvement of NOX4 in A $\beta$ synthesis and A11 production.

\section{Materials and Methods}

\subsection{Animals}

A meta-analysis of recent global data has shown that the prevalence of PD is more frequent in men than in women aged 50-79 years [53,54]. A total of 96 male C57/BL6 mice ((12 weeks, weighing 27-30 g; Samtako BioKorea. Co. Ltd., Osan, Gyeonggi Korea; 24 sham control mice (sham control) and 72 6-OHDA injected mice, 6-OHDA, Sigma-Aldrich, Saint Louis, MO, USA)) were enrolled in this study and maintained in a room at $22{ }^{\circ} \mathrm{C}$ under a $12 \mathrm{~h}$ light/dark cycle; chow and water were provided ad libitum. The room was illuminated by incandescent lamps (luminous flux, 11.77 lumen). Animal treatments, including anesthesia and euthanasia, were carried out in accordance with the Principle of Laboratory Animal Care (NIH publication No. 85-23, revised 1985). All experimental procedures were approved by the Animal Experiment Review Board of Institutional Animal Care and Use Committee (IACUC) of Konkuk University (Permit Number: KU16191; permission date: 22 November 2016).

\subsection{Animal Treatment and Unilateral 6-OHDA Lesion in MFB}

Under the ketamine $(50 \mathrm{mg} / \mathrm{kg}$ ) and xylazine $(5 \mathrm{mg} / \mathrm{kg})$ mixture through intraperitoneal (i.p.) injection, mice in the 6-OHDA group were fixed in a stereotaxic apparatus (Stoelting Co., Wood Dale, IL, USA), and then an incision was made on the scalp. The 6-OHDA solution $(1,2$, or $3 \mu \mathrm{g} / 2 \mu \mathrm{L} 6-\mathrm{OHDA}$ dissolved in $0.9 \%$ saline containing $0.01 \%$ ascorbic acid as antioxidants) was injected unilaterally into the MFB using a $10 \mu \mathrm{L}$ Hamilton microsyringe at one site of MFB using the following coordinates according to the Allen Mouse Brain Atlas [55-57]: $1.0 \mathrm{~mm}$ anterior to the bregma; $1.2 \mathrm{~mm}$ lateral to the midline; and $4.0 \mathrm{~mm}$ below the dura mater. Injections were carried out at a rate of $0.2 \mu \mathrm{L} / \mathrm{min}$ and a volume of $2 \mu \mathrm{L}$ was injected in the site. The needle was left at the injected sites for $5 \mathrm{~min}$ before being withdrawn. Mice in the control group received the same volume of saline in the same injected sites ( $n=12$ /group).

\subsection{Apomorphine-Induced Rotation.}

The animals were injected subcutaneously with $0.5 \mathrm{mg} / \mathrm{kg}$ apomorphine hydrochloride (APO, Sigma-Aldrich, St. Louis, MO, USA). The effect of APO on motor asymmetry and the rotation to uninjured side (to the left in our study) in a $60 \mathrm{~min}$ period were recorded by two examiners that were blinded to animal states. All mice were measured at 4 weeks after 6-OHDA injection [57].

\subsection{Immunohistochemistry}

Following perfusion with saline and $4 \%$ paraformaldehyde in phosphate-buffered saline (PBS, GibcoBRL, Gaithersburg, MD, USA), brains were removed, and the forebrain and midbrain blocks were immersion-fixed in $4 \%$ paraformaldehyde and cryoprotected in sucrose. Serial coronal sections ( $30 \mu \mathrm{m})$ were cut on a cryostat, collected in cryopreservative, and stored at $-20^{\circ} \mathrm{C}$. For immunolabeling studies, sections were incubated with a blocking solution (5\% horse serum and $0.3 \%$ Triton X-100 in PBS, pH 7.5) and then with primary antibody at $4{ }^{\circ} \mathrm{C}$ overnight. Mouse monoclonal anti-TH antibody (MAB318, 
1:2000) was obtained from EMD Millipore (Billerica, MA, USA). Next, sections were incubated with biotinylated goat anti-mouse IgG secondary antibodies (BA-9200,1:200, Vector Laboratories, Burlingame, CA, USA) in a blocking solution at room temperature for $1 \mathrm{~h}$. The sections were incubated with avidin-biotin-peroxidase complex (Vector Laboratories, Burlingame, CA, USA) in PBS/Triton $\mathrm{X}-100$ at room temperature for $1 \mathrm{~h}$. Signal labeling was achieved with $0.05 \%$ 3,30-diaminobenzidine and $0.003 \% \mathrm{H}_{2} \mathrm{O}_{2}$ (Vector Laboratories). Signals were evaluated on an inverted light microscope with $10 \times$ or $20 \times$ objectives (Carl Zeiss, Jena, Germany) [27].

\subsection{Western Blot and Dot Blot Analysis}

Tissues were washed with ice-cold PBS and lysed on ice in RIPA buffer (1\% PBS, 1\% NP-40, $0.5 \%$ sodium deoxycholate, $0.1 \%$ SDS) containing a protease inhibitor mixture (AEBSF, aprotinin, bestatin hydrochloride, E-64-[N-(trans-epoxysuccinyl)-L-leucine 4-guanidinobutylamide], leupeptin, pepstatin A) and phosphatase inhibitors (Sigma-Aldrich, St. Louis, MO, USA). A total of $30 \mu \mathrm{g}$ of soluble protein per lane was loaded in SDS-PAGE and electrotransferred onto a PVDF membrane. Specific protein bands were detected by using specific anti-TH (Millipore, USA), $\alpha$-synuclein $(\alpha$-syn, BD Bioscience, Franklin Lakes, NJ, USA), p- $\alpha$-syn (Abcam, Cambridge, UK), NOX1, NOX2, and NOX4 antibodies (Santa Cruz Biotechnology, Santa Cruz, CA, USA) and enhanced chemiluminescence (Pierce, Rockford, IL, USA) [29]. For dot blot, brain tissues were homogenized in a buffer containing $0.32 \mathrm{M}$ sucrose, $1 \mathrm{mM} \mathrm{NaHCO}_{3}, 1 \mathrm{mM} \mathrm{MgCl}_{2}, 0.5 \mathrm{mM} \mathrm{CaCl}_{2}$, and $1 \%$ of a protease inhibitor mixture (AEBSF, pepstatinA, E-64, bestatin, leupeptin, and aprotinin). The soluble fraction was obtained by centrifugation at $1000 \times g$ and $5 \mu \mathrm{L}$ of each sample, containing the same amount of protein, was spotted in a PVDF membrane. The membrane was air-dried for $4 \mathrm{~h}$ and blocked overnight at $4{ }^{\circ} \mathrm{C}$ in a 5\% nonfat dry milk TBST $(10 \mathrm{mM}$ Tris-HCl, pH 7.8, $100 \mathrm{mM} \mathrm{NaCl}, 0.05 \%$ Tween 20$)$ solution. Protein spots were detected using the primary antibodies ( $\alpha$-syn, BD Bioscience, USA; $p$ - $\alpha$-syn, Abcam, Cambridge, UK, Amyloid beta, A $\beta$, BioLegend (6E10), San Diego, CA, USA; A11 oligomer, Invitrogen, Waltham, MA USA) and secondary antibody conjugated to hydrogen peroxidase followed by enhanced chemiluminescence (ECL) detection [29].

\subsection{Behavior Test}

The MWM test was employed to evaluate the learning and memory of mice [23]. The MWM consisted of a large circular pool (150 cm in diameter, $45 \mathrm{~cm}$ in height), filled to a depth of $30 \mathrm{~cm}$ with water that was maintained at $28 \pm 1^{\circ} \mathrm{C}$. The water was made opaque using a nontoxic white-colored dye. The tank was divided into four equal quadrants using two threads that had been fixed at right angles to each other on the rim of the pool. A submerged platform $(15 \mathrm{~cm}$ in diameter) painted in white was placed inside the target quadrants of this pool, $1.5 \mathrm{~cm}$ below the surface of the water. The position of the platform was not changed throughout the training session. Four consecutive sessions, each consisting of five trials for 2 days (alternating two or three trials per day) was conducted over eight consecutive days. The hidden platform was always placed in the southeast quadrant of the pool. The mouse was gently placed in the water of the pool between quadrants, facing the wall of the pool, and the drop location was changed for each trial. The mice were then allowed $60 \mathrm{~s}$ to locate the submerged platform and were allowed to stay on the platform for another $30 \mathrm{~s}$. If the mice failed to find the platform within $60 \mathrm{~s}$, it was guided gently onto the platform and allowed to remain there for $30 \mathrm{~s}$. The intertrial interval was $1 \mathrm{~min}$. Performance accuracy was evaluated based on the analysis of the search error and the time latency data of all trials. A probe trial was conducted at $1 \mathrm{~min}$ after every $10^{\text {th }}$ training trial. The entire training procedure included two probe trials for each rat, during which the mice swam with the platform retracted to the bottom of the pool for $30 \mathrm{~s}$. After recording the swimming path, the platform was raised to its normal position for completion of the trial. The time spent swimming in the target quadrant of the retracted platform was used as a parameter for the retention of spatial memory [23]. 


\subsection{Double-Fluorescence Immunostaining of Tissues}

Free-floating sections $(30 \mu \mathrm{m})$ were incubated in $0.1 \mathrm{M}$ PBS containing $5 \%$ normal donkey serum and $0.3 \%$ Triton $\mathrm{X}-100$ for $1 \mathrm{~h}$, and subsequently incubated overnight with specific primary antibodies (Tuj-1, 1:1000, BioLegend, San Diego, CA, USA; $\alpha$-syn, 1:1000, BD Bioscience, USA; p- $\alpha$-syn, 1:1000, Abcam, Cambridge, UK, Amyloid beta, A $\beta$, 1:1000, BioLegend (6E10), San Diego, CA, USA; A11, 1:1000, Invitrogen, Waltham, MA USA; NOX4 (1:500, Santa Cruz Biotechnology, USA) in 2\% normal donkey serum (Vector Laboratories, Burlingame, CA, USA) in PBS at 4 and incubated with a 1:200 dilution of Alexa Fluor-conjugated donkey anti-rabbit (488) or donkey anti-mouse (546) antibodies (Invitrogen, Grand Island, NY, USA) for $1 \mathrm{~h}$ at room temperature and mounted on glass slides using Vectashield (Vector Laboratories, Burlingame, CA, USA). Fluorescent signals were evaluated on a confocal microscope (LSM 710, Carl Zeiss, Oberkochen, Germany) [29].

\subsection{Quantitative Analysis}

Sections including the hippocampus from six mice per group were subjected to analysis. Six regions of interests (ROIs) of $0.1 \mathrm{~mm}^{2}$ per one section in the hippocampus $(1.5 \sim 2.5 \mathrm{~mm}$ posterior to bregma) were selected. The number of TH-, Tuj-1-, $\alpha$-syn-, p- $\alpha$-syn-, A $\beta-$, NOX4-, A11 oligomer-, or EGFP-positive cells was counted in each ROI and averaged. Data are represented as a percentage of total cell and signal-positive cell counts. All quantitative analyses were carried out in a blind manner.

\subsection{Establishment of U6-NOX4 shRNA-CMV-EGFP/AAV and AAV Vector and AAV Viral Package.}

The U6 promoter-driven shRNA expression system was established in the AAV2 vector. EGFP expression was separately controlled by a CMV promoter as a marker for the transduction efficiency. NOX4 shRNA was designed based on the siRNA sequence which efficiently knocked down NOX4 expression in HT22 cells. Mouse NOX4 shRNA sequence (5'-AGCTTAAGCAACATTTGGTGTCCACTTTAATTCAAGAGATTAAAGTGGACACCAAATGTTG CTTTTTTTTG-3') was inserted between HindIII and EcoRI sites in the U6-CMV-EGFP/AAV vector. Both Scb shRNA and NOX4 shRNA/AAV were co-transfected with pHelper and pAAV-RC to HEK293 cells using a standard calcium phosphate method. After $72 \mathrm{~h}$, the cells were harvested and crude recombinant AAV (rAAV) vector solutions were obtained by repeated freeze/thaw cycles. The cleared crude lysate was then applied on a heparin-agarose column (Sigma, St. Louis, MO). After all the lysate went through the column, the matrix was washed twice with $25 \mathrm{~mL}$ of PBS (pH 7.4, $0.1 \mathrm{M} \mathrm{NaCl})$. The virus was then eluted with $15 \mathrm{~mL}$ of PBS ( $\mathrm{pH} 7.4,0.4 \mathrm{M} \mathrm{NaCl})$. The elutes was concentrated to about $1 \mathrm{ml}$ with a Millipore Centriplus YM-30 Centrifugal Filter by centrifugation at $4000 \mathrm{rpm}$ for $15-40 \mathrm{~min}$. To adjust the $\mathrm{NaCl}$ concentration to physiological levels, the filter device was refilled with PBS ( $\mathrm{pH} 7.4$ ), and the virus was concentrated to 250-300 $\mu \mathrm{L}$ again. After removal of the virus-containing solution, the membrane of the filter device was washed three times with $100 \mu \mathrm{l}$ of PBS (pH 7.4), which was added to the main part of the recombinant AAV2. The fractions containing high-titer $\mathrm{rAAV}$ vectors were collected and used for injection into animals. The number of rAAV genome copies was semiquantified by PCR within the CMV promoter region using primers 5'-GACGTCAATAATGACGTATG-3' and 5'-GGTAATAGCGATGACTAATACG-3'. The final titers were $5.5 \times 10^{11}$ genomes $/ \mathrm{mL}\left(\mathrm{rAAV} 2-\mathrm{Scb}\right.$ shRNA), and $6.5 \times 10^{11}$ genomes $/ \mathrm{mL}(\mathrm{rAAV} 2-\mathrm{NOX} 4$ shRNA) [27].

\subsection{Adeno-Associated Virus 2-Mediated NOX4 Knockdown}

AAV particles containing either NOX4 shRNA/AAV or Scb shRNA/AAV were stereotaxically injected into the hippocampal DG for 3 weeks before 6-OHDA or sham operation ( $n=12$ /group). Mice were deeply anesthetized (ketamine and xylazine mixture $30 \mathrm{mg} / \mathrm{kg}$, intraperitoneal) and placed in a mouse stereotaxic apparatus. NOX4 shRNA/AAV and Scb shRNA/AAV were then injected into both sites in the hippocampal DG (coordinate: anteroposterior, $-2.0 \mathrm{~mm}$; mediolateral, $-1.5 \mathrm{~mm}$; 
dorsoventral, $-2.25 \mathrm{~mm}$ ). A total of $1 \times 10^{11}$ genome copy $/ \mathrm{mL}$ recombinant AAV particles encoding NOX4 shRNA, or Scb shRNA diluted in $2 \mu \mathrm{L}$ ice-cold sterilized PBS were used in every animal. The injection rate was $0.5 \mu \mathrm{L} / \mathrm{min}$, and the syringe was kept in place for an additional 5 min before being retracted slowly. Mice were subjected to PBS or 6-OHDA injection after 3 weeks ( $n=12$ per group). The mice were allocated into four groups: sham-operated mice injected with Scb shRNA/AAV particles (Scb shRNA control, $n=12$ ); sham-operated mice injected with Nox4 shRNA/AAV particles (Nox4 shRNA control, $n=12$ ); 6-OHDA-injected mice with Scb shRNA/AAV particles (Scb shRNA 6-OHDA, $n=12$ ); and 6-OHDA-injected mice with NOX4 shRNA/AAV particles (Nox4 shRNA 6-OHDA, $n=12$ ). Twelve mice per group were used for the behavioral test, and 6 mice per group were used for the histological and biochemical studies.

\subsection{NOX Activity Assay}

NADPH oxidase activity was measured by a lucigenin-derived chemiluminescence assay as described [21-23]. Briefly, 5-7 mg homogenized protein was incubated with its substrate NADPH $(100 \mathrm{mM})$ in a phosphate buffer $(50 \mathrm{mM}, \mathrm{pH} 7.0)$ containing $150 \mathrm{mM} \mathrm{NaCl}$ and $1 \mathrm{mM}$ EGTA for $15 \mathrm{~min}$, followed by an addition of $5 \mathrm{mM}$ lucigenin for $15 \mathrm{~min}$ in dark. The chemiluminescent signal (photon emission) was measured using a Turner 20/20 luminometer (Turner Designs, Sunnyvale, CA, USA). No activity could be measured in the absence of NADPH [58].

\subsection{Novel Object Recognition Test}

The mice were placed in a $40 \times 40 \times 40 \mathrm{~cm}$ (height)-sized box and allowed to equilibrate to the testing area $10 \mathrm{~min}$ per day for 3 days. After $24 \mathrm{~h}$, two objects were placed in the testing area and then, the mouse was allowed to explore the two objects in the testing area for $5 \mathrm{~min}$ before being returned to the cage. After a $3 \mathrm{~h}$ interval, one of the objects was either relocated or replaced with a new object and the mice were allowed to explore the testing area once again for $2 \mathrm{~min}[23,59]$. The intertrial interval between these two tests was $24 \mathrm{~h}$. Exploring the novel object was defined if the center of the mouse' head was oriented within $45^{\circ}$ of the object and within $4 \mathrm{~cm}$ of it. Climbing over or sitting on an object was not included. A video camera was positioned over the arena, and exploratory behaviors were videotaped for later analysis. Exploratory time spent for novel objects was recorded, and the discrimination ratio was computed as [(time spent exploring novel object - time spent exploring familiar object)/total time spent exploring both objects] in a blind manner [23].

\subsection{Data Analysis and Statistics}

The MWM test was analyzed using a two-way repeated-measures ANOVA, followed by a post hoc least significant differences multiple comparisons test. The APO-induced rotation, swimming speed, probe test, NOR test, intensities of western blot, dot blot, and RT-PCR results, and cell counts after immunostaining were analyzed using a one-way ANOVA followed by a Newman-Keuls multiple comparisons test. If the value to be compared is a comparison between the two groups, a t-test was performed. Data are expressed as percentages of values obtained in control conditions and are presented as mean \pm S.E.M. Null hypotheses of no differences were rejected if $p<0.05$. All data analyses were performed using the SPSS version 22.0 software (IBM Corporation, New York, USA). The correlation coefficient was used to measure the strength of the relationship between the relative changes of the latency time in MWM and protein expression s in hippocampus (GraphPad, San Diego, CA, USA).

Author Contributions: D.-H.C. and J.L. conceived and designed the experiments; I.-A.C., C.S.L., J.H.Y., D.-H.C. performed the experiments; D.-H.C. and I.-A.C. analyzed the data; I.-A.C., C.S.L., J.H.Y. and D.-H.C. contributed reagents/materials/analysis tools; D.-H.C. wrote the paper. 
Acknowledgments: This research was supported by Basic Science Research Program through the National Research Foundation of Korea (NRF) funded by the Ministry of Science, Information and Communications Technology (ICT) and Future Planning (NRF-2014R1A2A1A11050236 grant to DHC, and NRF-2017R1A2B4004837 grant to JL), and the National Research Foundation of Korea (NRF) grant funded by the Korean government (NRF-2016R1A5A2012284).

Conflicts of Interest: The authors declare no conflicts of interest.

$\begin{array}{ll}\text { Abbreviations } & \\ \text { NOX4 } & \text { NADPH oxidase-4 } \\ \text { NADPH } & \text { Nicotinamide adenine sinucleotide phosphate } \\ \text { PD } & \text { Parkinson's disease } \\ \text { PDD } & \text { Parkinson's disease with dementia } \\ \text { AD } & \text { Alzheimer disease } \\ \text { MCI } & \text { Mild cognitive impairment } \\ \text { MWM } & \text { Morris water maze } \\ \text { NOR } & \text { Novel object recognition } \\ \alpha \text {-syn } & \text { Alpha synuclein } \\ \text { p- } \alpha \text {-syn } & \text { Phosphorylated alpha-synuclein } \\ \text { A } \beta & \text { Amyloid beta } \\ \text { Tuj-1 } & \text { Neuron-specific class III beta-tubulin } \\ \text { 6-OHDA } & \text { 6-hydroxydopamine } \\ \text { DG } & \text { Dentate gyrus } \\ \text { SN } & \text { Substantia nigra } \\ \text { TH } & \text { Tyrosine hydroxylase } \\ \text { MFB } & \text { Medial forebrain bundle } \\ \text { APO } & \text { Apomorphine } \\ \text { Scb shRNA } & \text { Scrambled shRNA/AAV } \\ \text { rAAV } & \text { Recombinant AAV } \\ \text { EGFP } & \text { Enhanced green fluorescent protein } \\ \text { ANOVA } & \text { Analysis of variance } \\ \text { h } & \text { hour(s) } \\ & \\ & \end{array}$

\section{References}

1. Calabresi, P.; Castrioto, A.; Di Filippo, M.; Picconi, B. New experimental and clinical links between the hippocampus and the dopaminergic system in parkinson's disease. Lancet Neurol. 2013, 12, 811-821. [CrossRef]

2. Monchi, O.; Hanganu, A.; Bellec, P. Markers of cognitive decline in pd: The case for heterogeneity. Parkinsonism Relat. Disord. 2016, 24, 8-14. [CrossRef] [PubMed]

3. Irwin, D.J.; White, M.T.; Toledo, J.B.; Xie, S.X.; Robinson, J.L.; Van Deerlin, V.; Lee, V.M.; Leverenz, J.B.; Montine, T.J.; Duda, J.E.; et al. Neuropathologic substrates of parkinson disease dementia. Ann. Neurol. 2012, 72, 587-598. [CrossRef] [PubMed]

4. Irwin, D.J.; Lee, V.M.; Trojanowski, J.Q. Parkinson's disease dementia: Convergence of alpha-synuclein, tau and amyloid-beta pathologies. Nat. Rev. Neurosci. 2013, 14, 626-636. [CrossRef] [PubMed]

5. Compta, Y.; Parkkinen, L.; O'Sullivan, S.S.; Vandrovcova, J.; Holton, J.L.; Collins, C.; Lashley, T.; Kallis, C.; Williams, D.R.; de Silva, R.; et al. Lewy- and alzheimer-type pathologies in parkinson's disease dementia: Which is more important? Brain 2011, 134, 1493-1505. [CrossRef] [PubMed]

6. Jellinger, K.A.; Attems, J. Prevalence and impact of vascular and alzheimer pathologies in lewy body disease. Acta Neuropathol. 2008, 115, 427-436. [CrossRef] [PubMed]

7. Kovari, E.; Gold, G.; Herrmann, F.R.; Canuto, A.; Hof, P.R.; Bouras, C.; Giannakopoulos, P. Lewy body densities in the entorhinal and anterior cingulate cortex predict cognitive deficits in parkinson's disease. Acta Neuropathol. 2003, 106, 83-88. [PubMed] 
8. Jellinger, K.A. Morphological substrates of parkinsonism with and without dementia: A retrospective clinico-pathological study. In Neuropsychiatric Disorders An Integrative Approach; Springer: Vienna, Austria, 2007; pp. 91-104.

9. Jellinger, K.A.; Seppi, K.; Wenning, G.K.; Poewe, W. Impact of coexistent alzheimer pathology on the natural history of parkinson's disease. J. Neural Transm. 2002, 109, 329-339. [CrossRef]

10. Petrou, M.; Dwamena, B.A.; Foerster, B.R.; MacEachern, M.P.; Bohnen, N.I.; Muller, M.L.; Albin, R.L.; Frey, K.A. Amyloid deposition in parkinson's disease and cognitive impairment: A systematic review. Mov. Disord. 2015, 30, 928-935. [CrossRef]

11. Jellinger, K.A. Significance of brain lesions in parkinson disease dementia and lewy body dementia. Front. Neurol. Neurosci. 2009, 24, 114-125.

12. Halliday, G.M.; Holton, J.L.; Revesz, T.; Dickson, D.W. Neuropathology underlying clinical variability in patients with synucleinopathies. Acta Neuropathol. 2011, 122, 187-204. [CrossRef]

13. Kalaitzakis, M.E.; Graeber, M.B.; Gentleman, S.M.; Pearce, R.K. Striatal beta-amyloid deposition in parkinson disease with dementia. J. Neuropathol. Exp. Neurol. 2008, 67, 155-161. [CrossRef] [PubMed]

14. Klunk, W.E.; Engler, H.; Nordberg, A.; Wang, Y.; Blomqvist, G.; Holt, D.P.; Bergstrom, M.; Savitcheva, I.; Huang, G.F.; Estrada, S.; et al. Imaging brain amyloid in alzheimer's disease with pittsburgh compound-b. Ann. Neurol. 2004, 55, 306-319. [CrossRef] [PubMed]

15. Foo, H.; Mak, E.; Chander, R.J.; Ng, A.; Au, W.L.; Sitoh, Y.Y.; Tan, L.C.; Kandiah, N. Associations of hippocampal subfields in the progression of cognitive decline related to parkinson's disease. Neuroimage Clin. 2017, 14, 37-42. [CrossRef] [PubMed]

16. Kehagia, A.A.; Barker, R.A.; Robbins, T.W. Neuropsychological and clinical heterogeneity of cognitive impairment and dementia in patients with parkinson's disease. Lancet Neurol. 2010, 9, 1200-1213. [CrossRef]

17. Lisman, J.; Grace, A.A.; Duzel, E. A neohebbian framework for episodic memory; role of dopamine-dependent late ltp. Trends Neurosci. 2011, 34, 536-547. [CrossRef] [PubMed]

18. Costa, C.; Sgobio, C.; Siliquini, S.; Tozzi, A.; Tantucci, M.; Ghiglieri, V.; Di Filippo, M.; Pendolino, V.; de Iure, A.; Marti, M.; et al. Mechanisms underlying the impairment of hippocampal long-term potentiation and memory in experimental parkinson's disease. Brain 2012, 135, 1884-1899. [CrossRef] [PubMed]

19. Churchyard, A.; Lees, A.J. The relationship between dementia and direct involvement of the hippocampus and amygdala in parkinson's disease. Neurology 1997, 49, 1570-1576. [CrossRef]

20. Camicioli, R.; Moore, M.M.; Kinney, A.; Corbridge, E.; Glassberg, K.; Kaye, J.A. Parkinson's disease is associated with hippocampal atrophy. Mov. Disord. 2003, 18, 784-790. [CrossRef]

21. Tam, C.W.; Burton, E.J.; McKeith, I.G.; Burn, D.J.; O’Brien, J.T. Temporal lobe atrophy on mri in parkinson disease with dementia: A comparison with alzheimer disease and dementia with lewy bodies. Neurology 2005, 64, 861-865. [CrossRef]

22. Jokinen, P.; Bruck, A.; Aalto, S.; Forsback, S.; Parkkola, R.; Rinne, J.O. Impaired cognitive performance in parkinson's disease is related to caudate dopaminergic hypofunction and hippocampal atrophy. Parkinsonism Relat. Disord. 2009, 15, 88-93. [CrossRef] [PubMed]

23. Choi, D.H.; Lee, K.H.; Kim, J.H.; Seo, J.H.; Kim, H.Y.; Shin, C.Y.; Han, J.S.; Han, S.H.; Kim, Y.S.; Lee, J. Nadph oxidase 1, a novel molecular source of ros in hippocampal neuronal death in vascular dementia. Antioxid. Redox Signal. 2014, 21, 533-550. [CrossRef] [PubMed]

24. Choi, D.H.; Lee, J. A mini-review of the nadph oxidases in vascular dementia: Correlation with noxs and risk factors for vad. Int. J. Mol. Sci. 2017, 18, 2500. [CrossRef] [PubMed]

25. Ansari, M.A.; Scheff, S.W. Nadph-oxidase activation and cognition in alzheimer disease progression. Free Radic. Biol. Med. 2011, 51, 171-178. [CrossRef] [PubMed]

26. Bruce-Keller, A.J.; Gupta, S.; Parrino, T.E.; Knight, A.G.; Ebenezer, P.J.; Weidner, A.M.; LeVine, H., 3rd; Keller, J.N.; Markesbery, W.R. Nox activity is increased in mild cognitive impairment. Antioxid. Redox Signal. 2010, 12, 1371-1382. [CrossRef] [PubMed]

27. Choi, D.H.; Cristovao, A.C.; Guhathakurta, S.; Lee, J.; Joh, T.H.; Beal, M.F.; Kim, Y.S. Nadph oxidase 1-mediated oxidative stress leads to dopamine neuron death in parkinson's disease. Antioxid. Redox Signal. 2012, 16, 1033-1045. [CrossRef]

28. Cristovao, A.C.; Choi, D.H.; Baltazar, G.; Beal, M.F.; Kim, Y.S. The role of nadph oxidase 1-derived reactive oxygen species in paraquat-mediated dopaminergic cell death. Antioxid. Redox Signal. 2009, 11, 2105-2118. [CrossRef] 
29. Cristovao, A.C.; Guhathakurta, S.; Bok, E.; Je, G.; Yoo, S.D.; Choi, D.H.; Kim, Y.S. Nadph oxidase 1 mediates alpha-synucleinopathy in parkinson's disease. J. Neurosci. 2012, 32, 14465-14477. [CrossRef]

30. Harding, A.J.; Halliday, G.M. Cortical lewy body pathology in the diagnosis of dementia. Acta Neuropathol. 2001, 102, 355-363.

31. Hurtig, H.I.; Trojanowski, J.Q.; Galvin, J.; Ewbank, D.; Schmidt, M.L.; Lee, V.M.; Clark, C.M.; Glosser, G.; Stern, M.B.; Gollomp, S.M.; et al. Alpha-synuclein cortical lewy bodies correlate with dementia in parkinson's disease. Neurology 2000, 54, 1916-1921. [CrossRef]

32. Ullman, M.T.; Pullman, M.Y. A compensatory role for declarative memory in neurodevelopmental disorders. Neurosci. Biobehav. Rev. 2015, 51, 205-222. [CrossRef] [PubMed]

33. Zhang, X.; Bai, L.; Zhang, S.; Zhou, X.; Li, Y.; Bai, J. Trx-1 ameliorates learning and memory deficits in mptp-induced parkinson's disease model in mice. Free Radic. Biol. Med. 2018, 124, 380-387. [CrossRef] [PubMed]

34. Hely, M.A.; Reid, W.G.; Adena, M.A.; Halliday, G.M.; Morris, J.G. The sydney multicenter study of parkinson's disease: The inevitability of dementia at 20 years. Mov. Disord. 2008, 23, 837-844. [CrossRef] [PubMed]

35. Kempster, P.A.; O'Sullivan, S.S.; Holton, J.L.; Revesz, T.; Lees, A.J. Relationships between age and late progression of parkinson's disease: A clinico-pathological study. Brain 2010, 133, 1755-1762. [CrossRef] [PubMed]

36. Aarsland, D.; Andersen, K.; Larsen, J.P.; Lolk, A.; Kragh-Sorensen, P. Prevalence and characteristics of dementia in parkinson disease: An 8-year prospective study. Arch. Neurol. 2003, 60, 387-392. [CrossRef]

37. Halliday, G.; Hely, M.; Reid, W.; Morris, J. The progression of pathology in longitudinally followed patients with parkinson's disease. Acta Neuropathol. 2008, 115, 409-415. [CrossRef]

38. Levy, G.; Schupf, N.; Tang, M.X.; Cote, L.J.; Louis, E.D.; Mejia, H.; Stern, Y.; Marder, K. Combined effect of age and severity on the risk of dementia in parkinson's disease. Ann. Neurol. 2002, 51, 722-729. [CrossRef]

39. Williams-Gray, C.H.; Evans, J.R.; Goris, A.; Foltynie, T.; Ban, M.; Robbins, T.W.; Brayne, C.; Kolachana, B.S.; Weinberger, D.R.; Sawcer, S.J.; et al. The distinct cognitive syndromes of parkinson's disease: 5 year follow-up of the campaign cohort. Brain 2009, 132, 2958-2969. [CrossRef]

40. Emre, M.; Aarsland, D.; Brown, R.; Burn, D.J.; Duyckaerts, C.; Mizuno, Y.; Broe, G.A.; Cummings, J.; Dickson, D.W.; Gauthier, S.; et al. Clinical diagnostic criteria for dementia associated with parkinson's disease. Mov. Disord. 2007, 22, 1689-1707. [CrossRef] [PubMed]

41. Ma, Y.; Zhan, M.; OuYang, L.; Li, Y.; Chen, S.; Wu, J.; Chen, J.; Luo, C.; Lei, W. The effects of unilateral 6-ohda lesion in medial forebrain bundle on the motor, cognitive dysfunctions and vulnerability of different striatal interneuron types in rats. Behav. Brain Res. 2014, 266, 37-45. [CrossRef]

42. Apaydin, H.; Ahlskog, J.E.; Parisi, J.E.; Boeve, B.F.; Dickson, D.W. Parkinson disease neuropathology: Later-developing dementia and loss of the levodopa response. Arch. Neurol. 2002, 59, 102-112. [CrossRef] [PubMed]

43. Tsuboi, Y.; Uchikado, H.; Dickson, D.W. Neuropathology of parkinson's disease dementia and dementia with lewy bodies with reference to striatal pathology. Parkinsonism Relat. Disord. 2007, 13, S221-S224. [CrossRef]

44. Parkkinen, L.; Pirttila, T.; Alafuzoff, I. Applicability of current staging/categorization of alpha-synuclein pathology and their clinical relevance. Acta Neuropathol. 2008, 115, 399-407. [CrossRef] [PubMed]

45. Parkkinen, L.; Kauppinen, T.; Pirttila, T.; Autere, J.M.; Alafuzoff, I. Alpha-synuclein pathology does not predict extrapyramidal symptoms or dementia. Ann. Neurol. 2005, 57, 82-91. [CrossRef] [PubMed]

46. Pletnikova, O.; West, N.; Lee, M.K.; Rudow, G.L.; Skolasky, R.L.; Dawson, T.M.; Marsh, L.; Troncoso, J.C. Abeta deposition is associated with enhanced cortical alpha-synuclein lesions in lewy body diseases. Neurobiol. Aging 2005, 26, 1183-1192. [CrossRef] [PubMed]

47. Duda, J.E.; Giasson, B.I.; Mabon, M.E.; Lee, V.M.; Trojanowski, J.Q. Novel antibodies to synuclein show abundant striatal pathology in lewy body diseases. Ann. Neurol. 2002, 52, 205-210. [CrossRef] [PubMed]

48. Bruce-Keller, A.J.; Gupta, S.; Knight, A.G.; Beckett, T.L.; McMullen, J.M.; Davis, P.R.; Murphy, M.P.; Van Eldik, L.J.; St Clair, D.; Keller, J.N. Cognitive impairment in humanized appxps1 mice is linked to abeta(1-42) and nox activation. Neurobiol. Dis. 2011, 44, 317-326. [CrossRef]

49. Kan, H.; Hu, W.; Wang, Y.; Wu, W.; Yin, Y.; Liang, Y.; Wang, C.; Huang, D.; Li, W. Nadph oxidase-derived production of reactive oxygen species is involved in learning and memory impairments in 16-month-old female rats. Mol. Med. Rep. 2015, 12, 4546-4553. [CrossRef] 
50. Han, B.H.; Zhou, M.L.; Johnson, A.W.; Singh, I.; Liao, F.; Vellimana, A.K.; Nelson, J.W.; Milner, E.; Cirrito, J.R.; Basak, J.; et al. Contribution of reactive oxygen species to cerebral amyloid angiopathy, vasomotor dysfunction, and microhemorrhage in aged tg2576 mice. Proc. Natl. Acad. Sci. USA 2015, 112, E881-E890. [CrossRef]

51. Park, L.; Zhou, P.; Pitstick, R.; Capone, C.; Anrather, J.; Norris, E.H.; Younkin, L.; Younkin, S.; Carlson, G.; McEwen, B.S.; et al. Nox2-derived radicals contribute to neurovascular and behavioral dysfunction in mice overexpressing the amyloid precursor protein. Proc. Natl. Acad. Sci. USA 2008, 105, 1347-1352. [CrossRef]

52. Dugan, L.L.; Ali, S.S.; Shekhtman, G.; Roberts, A.J.; Lucero, J.; Quick, K.L.; Behrens, M.M. Il-6 mediated degeneration of forebrain gabaergic interneurons and cognitive impairment in aged mice through activation of neuronal nadph oxidase. PLoS ONE 2009, 4, e5518. [CrossRef] [PubMed]

53. Hirsch, L.; Jette, N.; Frolkis, A.; Steeves, T.; Pringsheim, T. The incidence of parkinson's disease: A systematic review and meta-analysis. Neuroepidemiology 2016, 46, 292-300. [CrossRef] [PubMed]

54. Das, N.R.; Sharma, S.S. Cognitive impairment associated with parkinson's disease: Role of mitochondria. Curr. Neuropharmacol. 2016, 14, 584-592. [CrossRef] [PubMed]

55. Franklin, K.B.J.; Paxinos, G. The Mouse Brain in Stereotaxic Coordinates; Academic Press: San Diego, CA, USA, 1997.

56. Boix, J.; Padel, T.; Paul, G. A partial lesion model of parkinson's disease in mice-characterization of a 6-ohda-induced medial forebrain bundle lesion. Behav. Brain Res. 2015, 284, 196-206. [CrossRef] [PubMed]

57. Choi, D.H.; Kim, J.H.; Kim, S.M.; Kang, K.; Han, D.W.; Lee, J. Therapeutic potential of induced neural stem cells for parkinson's disease. Int. J. Mol. Sci. 2017, 18, 224. [CrossRef] [PubMed]

58. Choi, D.H.; Kim, J.H.; Seo, J.H.; Lee, J.; Choi, W.S.; Kim, Y.S. Matrix metalloproteinase-3 causes dopaminergic neuronal death through nox1-regenerated oxidative stress. PLoS ONE 2014, 9, e115954. [CrossRef] [PubMed]

59. Choi, B.R.; Lee, S.R.; Han, J.S.; Woo, S.K.; Kim, K.M.; Choi, D.H.; Kwon, K.J.; Han, S.H.; Shin, C.Y.; Lee, J.; et al. Synergistic memory impairment through the interaction of chronic cerebral hypoperfusion and amlyloid toxicity in a rat model. Stroke 2011, 42, 2595-2604. [CrossRef]

(C) 2019 by the authors. Licensee MDPI, Basel, Switzerland. This article is an open access article distributed under the terms and conditions of the Creative Commons Attribution (CC BY) license (http:/ / creativecommons.org/licenses/by/4.0/). 